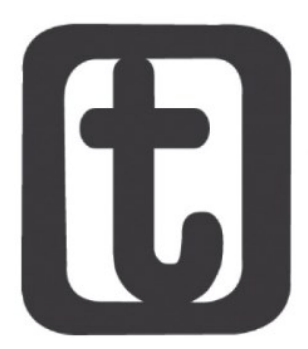

\title{
TRABAJO SOCIAL, DERECHOS HUMANOS Y FALSA CONSCIENCIA: ELEMENTOS PARA UNA COMPRENSIÓN CRÍTICA
}

\author{
Social work, human rights and false awareness: \\ elements for a critical understanding
}

\section{César Villegas-Herrera*}

\begin{abstract}
RESUMEN
El presente trabajo aborda la forma en que una profesión como Trabajo Social ha construido a partir de los Derechos Humanos, dos posicionamientos ideológicos que lejos de facilitar su comprensión y recuperación crítica, han generado por el contrario una comprensión deshistorizada de los mismos.
\end{abstract}

PALABRAS CLAVE

Derechos Humanos. Trabajo Social. Ideología. Ética.

\begin{abstract}
The present work deals with the way in which a profession as Social Work has constructed from the Human Rights, two ideological positions that far from facilitating their understanding and critical recovery, have generated on the contrary a dehistorized understanding of them.
\end{abstract}

\section{KEYWORDS}

Human Rights. Social Work. Ideology. Etic.

\section{INTRODUCCIÓN}

La investigación bibliográfica que permitió la reflexión plasmada en este artículo, permite apreciar que ya sea en una vía u otra, los Derechos Humanos han sido incorporados en la profesión, como una especie de ethos profesional, que entre otras cosas define la defensa y garantía de los derechos como una finalidad central para el Trabajo Social.

Ahora bien, el posicionamiento de este ethos, o deber ser para la profesión se ha colocado de manera asimétrica. Ya sea por el sesgo conservador de raigambre liberal que domina la discusión y posicionamiento original de la temática, que concibe los derechos humanos (y aún las propios personas) de una forma abstracta; o bien por cierta crítica ultra izquierdista que los concibe como mera creación y reproducción del sistema capitalista. Ambas posiciones comparten un mismo sesgo: la deshistorización de los Derechos Humanos; ya

\footnotetext{
* Profesor adjunto de Servicio Social da Facultad de Ciências Sociales de la National Universidad de Costa Rica. Avenida 1, Calle 9 Heredia 86, 3000, Costa Rica. ORC ID: <https://orcid.org/0000-0002-9403-8661>. Email:<cvillegash@gmail.com>.
}

DOI 10.22422/temporalis.2018v18n36p110-126 


\section{temporalis}

HERRERA-VILLEGAS, CÉSAR

sea en la consideración de los mismos como absolutos morales, así como en la invisibilización de la procesualidad histórica vinculada a la lucha y resistencia que los hace posible. Es por ello que en este trabajo se sostiene que desde un punto de vista ideológico, los Derechos Humanos se han incorporado esencialmente como falsa consciencia.

El presente artículo pretende un abordaje crítico para la recuperación histórica que se ha hecho de la temática para la profesión. Para ello se iniciará con una exposición de las principales líneas argumentativas respecto a la fundamentación en Derechos Humanos desde las cuales se orienta el análisis del presente trabajo. En un segundo apartado se analizará los rasgos centrales que particularizan la tendencia ideológica conservadurista de los Derechos Humanos en la profesión de Trabajo Social, para inmediatamente analizar los rasgos que asume la presuntamente antagónica crítica ultraizquierdista. Finalmente, se aportan una serie de consideraciones teóricas que se juzgan indispensables para la historización de los derechos humanos y para una consecuente recuperación crítica desde el Trabajo Social.

\section{FALSA CONSCIENCIA Y DESHISTORIZACIÓN DE LOS DERECHOS HUMANOS.}

El concepto de ideología tiene en la tradición marxista clásica una connotación negativa, por cuanto hace alusión a una forma de encubrimiento de la realidad objetiva por parte de la consciencia, y para decirlo de manera más precisa, un encubrimiento de las condiciones de opresión en la sociedad capitalista. Al respecto, Löwy (2010) plantea que:

Para Marx, claramente, ideologia é um conceito pejorativo, um conceito crítico que implica ilusão, ou se refere à consciência deformada da realidade que se dá através da ideologia dominante: as idéias das classes dominantes são as ideologias dominantes na sociedade. (LÖWY, 2010, p.12).

Tal como se aprecia, esta concepción plantea que las clases dominantes imponen en la sociedad una visión de mundo vinculada con sus intereses exclusivos de clase, con lo cual se origina un impacto en la consciencia de las clases dominadas, que trae a su vez como consecuencia objetiva la reproducción y conservación del orden económico establecido.

Se habla de ilusión, en tanto al producirse esta escisión entre la realidad objetivamente vivida y la forma subjetiva en que esta es apropiada; las clases dominadas se encuentran imposibilitadas para reconocer sus condiciones de opresión, y con ello las posibilidades de romper con las mismas. Dicho en términos sintéticos, la imposibilidad de comprender la historia, conlleva la imposibilidad de incidir en ella con una finalidad emancipatoria.

Ahora bien, esto no constituye una condición irreversible, dado que la posibilidad de romper con esta situación pasa precisamente por la necesidad de romper con la falsa consciencia de la clase dominante y actuar a partir de los propios intereses de clase objetivamente dominada.

Hecha esta reflexión, lo primero que hay que señalar es que en los debates habituales sobre Derechos Humanos, existe una sensibilidad dominante particular que se manifiesta a partir de dos formas concretas de deshistorización. La primera de ellas corresponde a una forma 


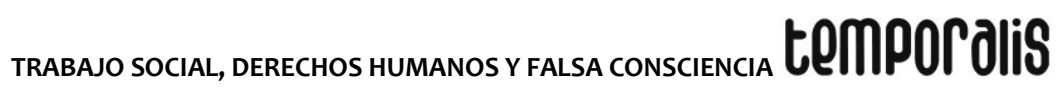

de escisión entre teoría y práctica, mientras que la segunda apunta hacia una comprensión axiológica de los Derechos Humanos en lo que respecta a su fundamentación.

La primera de ellas puede encontrarse en una consigna formulada por el jurista italiano Noberto Bobbio (1991) planteada de la siguiente forma: “El problema de fondo relativo a los derechos humanos no es hoy tanto el de justificarlos como el de protegerlos. Es un problema no filosófico, sino político." (p. 62).

Más allá de lo sugestiva que resulta la consigna, la misma trae dos implicaciones que abren paso a la deshistorización de los Derechos Humanos. Lo primero que hay que señalar es que esta propuesta es posible solo a partir de la ruptura entre la fundamentación de los derechos humanos (teoría) y las estrategias para protegerlos y garantizarlos (práxis); en donde la primera se presenta necesariamente como subordinada a la segunda, y en caso extremo como prescindible ${ }^{1}$.

Esta comprensión introduce un sesgo de carácter practicista muy a tono con cierta forma de pensamiento conservador, donde la protección de los derechos es reducida a un problema de carácter técnico-instrumental, con lo cual, se invisibilizan y se pasan por alto las condiciones históricas que posibilitaron la violación de dichos derechos. Esta forma de falsa consciencia, sin embargo, está limitada al campo retórico; ya que necesariamente no existen posibilidades de defender los derechos si no hay una consciencia previa (así sea falsa) de qué es un derecho, cuáles son sus límites de exigibilidad y sobre todo quien puede reclamarse como sujeto portador del mismo.

Esto nos lleva directamente a la segunda forma de deshistorización, que es la concepción axiológica de los mismos. Siguiendo a Gallardo (2004) en ella los Derechos Humanos pasan a ser comprendidos como valores, esto es que se asumen de manera autoevidente como algo necesariamente positivo, o planteado en términos sencillos como portadores de bienestar absoluto. En este caso, la falsa consciencia opera en el campo de la fundamentación la cual viene a darse en términos abstractos. Sobre este aspecto, la sensibilidad de las clases dominantes opera desde dos concepciones hegémonicas en materia de derechos humanos: el iusnaturalismo y el iuspositivismo.

La primera de ellas considera como fuente del derecho, la propia naturaleza del ser humano. Es de esta manera que se plantea que las personas cuentan con derechos que le son inherentes por su propia condición de humanidad, con independencia del contexto en el que vivan. Con ello se tiene una fundamentación de corte esencialista que apela a valores abstractos y absolutos tales como la dignidad o la solidaridad, así como una tendencia a apelar a una moral universal transhistórica, que puede ser de corte religioso o secular.

El iuspositivismo por otra parte, se opone (en apariencia) a la anterior desde una fundamentación jurídico formalista, esto es que concibe la existencia de los derechos

\footnotetext{
${ }^{1}$ Esta última consideración debe ser matizada, ya que a pesar del sesgo practicista señalado, el mismo Bobbio no lo sigue al pie de la letra, ya que buena parte de su obra está dedicada precisamente a la fundamentación filosófico-jurídica de los Derechos Humanos. El problema radica en el carácter reductivo de la cita, que al darle tanta centralidad a la efectividad en la protección de los derechos, termina dando a entender que esta constituye un problema que se resuelve exclusivamente en el campo de la acción.
} 


\section{tomporalis}

humanos en tanto se encuentren explícitamente reconocidos en el ordenamiento jurídico. En este sentido, los derechos existen exclusivamente como una condición formalmente dada, en la cual la norma constituye el límite de posibilidad de goce del mismo, así como el criterio para reconocer quién puede exigirlos y quién no.

Como puede apreciarse, existe en esta última concepción el desarrollo de una racionalidad claramente instrumental, en donde la ley no solo delimita la realidad, sino que la reproduce en el propio acto de regulación. Así mismo, esta fundamentación prescinde de la historia, ya que tanto los antecedentes como el devenir de las normas, se asumen como epifenómenos exteriores al derecho, y prescindibles en última instancia a la hora de su aplicación.

A pesar de que los puntos de partida de cada una muestran una presumible incompatibilidad, lo cierto es que la misma es aparencial, siendo que tal como se desarrolla más adelante, ambas concepciones axiológicas pueden llegar a ser complementarias. La razón de ello descansa en que ambas prescinden de la conflictividad social como factor contextual determinante para comprender la génesis, el desarrollo y el devenir de los derechos humanos ${ }^{2}$. Así mismo, el asumirlos como absolutos morales, conlleva la imposibilidad de criticarlos como producción humana susceptible de contradicción y alienación.

Es debido a todo lo anterior que en torno los Derechos Humanos puede operar discursivamente como una forma de falsa consciencia, que requeriría de una reflexión concreta que permita su ruptura. Esta es propuesta por Gallardo (2004), quien concibe los Derechos Humanos como el resultado de una procesualidad histórica heterogénea, en la que el conflicto constituye su núcleo central, y que tendría como fundamento central una concepción en la que los derechos son el resultado histórico de acciones de lucha, resistencia y movilización. En este planteamiento, los Derechos Humanos no existen como tales si no se testimonian en la vida cotidiana, y sobre todo si no se lucha por ellos.

La idea central Gallardo (2004), parte del criterio de que las asimetrías en las relaciones de poder entre dominantes y dominados, entre opresores y oprimidos, hace que exista una ruptura estructural entre lo que se dice y lo que se hace en materia de derechos. El resultado de ello es que la existencia formalizada de un derecho, no es garantía necesaria de goce del mismo, dada la desigualdad existente entre agentes sociales al acceso a recursos para exigir justicia3. Es de esta forma, que concluye que, en sociedades con una fuerte presencia

\footnotetext{
2 Una precisión es necesaria en este punto. Tanto el iusnaturalismo como el iuspositivismo reconocen la existencia de conflictos que violentan los Derechos Humanos, sin embargo, estos son asumidos como una situación de anormalidad y desviación, que puede y debe ser controlada hasta lograr un contexto favorable a los derechos. Dicho en otras palabras, el conflicto nunca es asumido como resultante de las estructuras económicas y sociales; ya que ello implicaría aceptar la incompatibilidad de su presunta universalidad con la forma en que se estructuran y reproducen las sociedades capitalistas.

De igual forma, el conflicto viene a ser reducido a su carácter de negación derechos, invisibilizando su papel dinamizador para el propio goce de los mismos.

3 En un artículo elaborado para el Semanario Universidad, titulado Justicia para pobres, Fernández (2017) presenta los resultados preliminares de una investigación de la siguiente manera: "Un estudio de Univisión Data, a partir de la revisión de 8.000 sentencias judiciales, descubrió que, en Costa Rica, en ciertos delitos, la probabilidad de que una persona sea condenada en juicio aumenta entre un $12 \%$ y $26 \%$ cuando tiene un
} 


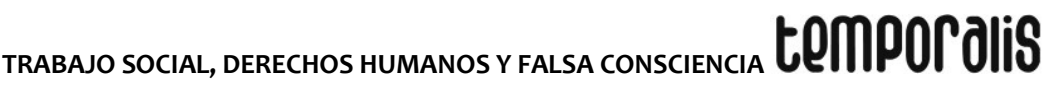

de desigualdad y violencia estructural, las posibilidades históricas de existencia de los Derechos Humanos están necesariamente atravesadas por la lucha, ya que, de no ser así estos corren el riesgo de volverse letra muerta, o en el peor de los casos, de ser eliminados del propio entramando jurídico ${ }^{4}$.

\section{TRABAJO SOCIAL, DERECHOS HUMANOS Y CONSERVADURISMO ÉTICO}

Las consideraciones previamente desarrolladas muestran la forma en que los Derechos Humanos pueden ser apropiados desde una ideología dominante, y que se viene a particularizar por la forma en que estos se abstraen respecto de la conflictividad social. Este recurso que ha sido caracterizado en este trabajo como una forma de falsa consciencia, ha operado a su vez de manera particular en el seno de la profesión.

Lo primero que hay que indicar es que la profesión de Trabajo Social ha asumido discursivamente los Derechos Humanos como un ethos profesional. La razón de ello tiene que ver con la confluencia de dos factores: por un lado, la forma en que los Derechos Humanos son definidos por organismos internacionales (esto es la versión oficial de los derechos humanos), y por otro, la sensibilidad y auto comprensión de un sector de la categoría profesional, que ha generado la apropiación de dicho discurso oficial a partir de una ideología conservadora que amalgama simultáneamente elementos iusnaturalistas y iuspositivistas.

Con respecto al primer factor, la siguiente definición de enfoque de derechos formulada por la Oficina Alto Comisionado de Naciones Unidas para los Derechos Humanos (OHCHR), muestra el punto de convergencia entre este y las concepciones más conservadoras respecto a la génesis y reproducción de la categoría profesional:

\begin{abstract}
El enfoque basado en los derechos humanos es un marco conceptual para el proceso de desarrollo humano que desde el punto de vista normativo está basado en las normas internacionales de derechos humanos y desde el punto de vista operacional está orientado a la promoción y la protección de los derechos humanos [... ] Desde la perspectiva de los derechos humanos, la caridad por sí sola no es suficiente. En un enfoque de derechos humanos, los planes, las políticas y los procesos de desarrollo están anclados en un sistema de derechos y de los correspondientes deberes establecidos por el derecho internacional (Resaltados míos) (OFICINA ALTO COMISIONADO DE NACIONES UNIDAS PARA LOS DERECHOS HUMANOS, 2006, p. 15).
\end{abstract}

Como puede apreciarse esta definición deja abiertos dos vínculos posibles con la profesión de Trabajo Social. Por un lado, la propuesta es confluyente con la tesis endogenista sobre la génesis del Trabajo Social, que entre otras cosas plantea la necesidad de romper con las protoformas de la profesión, entre ellas la caridad (Montaño, 1998). En este caso, a diferencia de la Reconceptualización que planteaba dicha posibilidad a partir del

\footnotetext{
defensor público." De este caso se extrae, que a pesar de que, desde un punto de vista formal, todos los seres humanos son iguales ante la ley, la imposibilidad de contar con los recursos económicos para pagar un abogado litigante se convierte en un factor trascendental para lograr acceso a un juicio justo.

${ }_{4}^{4}$ Piénsese, por ejemplo, en los derechos que son eliminados de las legislaciones laborales con el objetivo de favorecer la importación de capitales en los países periféricos, y la resistencia que desarrolla la clase trabajadora organizada con tal de seguir siendo titular de los mismos.
} 


\section{temporalis}

encarrilamiento de la profesión dentro de los márgenes de la ciencia, tenemos ahora que la posibilidad la ofrece la adopción de los Derechos Humanos como finalidad, ya que dicha teleología es alcanzable sólo a partir de la ruptura con las protoformas.

Por otra parte, esta definición oficial reconoce como espacio de realización de los Derechos Humanos a las políticas sociales. Siendo estas objetivizan las condiciones de trabajo profesional, puede apreciarse como esto permite realizar una rápida vinculación "sentido común" entre Trabajo Social y la materialización de los derechos.

Aquí es importante señalar que la procesualidad histórica que permite ambas operaciones (génesis y teleología) de vínculo entre Trabajo Social y Derechos Humanos es además abstracta, debido a que la relación pasado (protoformas)-presente (políticas sociales) se asume de una manera deshistorizada. A este punto se podría señalar que esto constituye una interpretación que, aunque plausible, resulta excesiva en tanto la definición de la Oficina Alto Comisionado de Naciones Unidas para los Derechos Humanos (2006) no menciona de manera específica a la profesión. Sin embargo, existe una mediación entre lo antes enunciado y una forma de falsa consciencia analizada en el apartado anterior, y es que las políticas sociales son asumidas también desde una postura axiológica, en la cual se asume de manera acrítica, que su función es la de viabilizar el alcance de metas vinculadas al desarrollo humano5. Esta reflexión puede ser expuesta en términos sintéticos de la siguiente manera: si los Derechos Humanos son esencialmente buenos, y las políticas sociales permiten su alcance y goce, es porque estas también son esencialmente buenas.

Es precisamente este aspecto el que posibilita la absorción particular de este discurso en una clave conservadora en el desarrollo de la profesión en Costa Rica. Al respecto, el conservadurismo puede definirse como una "[...] tendencia histórica, ideológico-cultural y política, que siendo afín a la sociedad burguesa guarda compromiso con su manutención y reproducción social" (VILLEGAS-HERRERA, 2016, p. 47).

En lo que respecta a la profesión de Trabajo Social, el autor señala que el conservadurismo ético en el Trabajo Social (para el caso costarricense) se ha caracterizado entre otros rasgos por el sostenimiento de un humanismo abstracto, la creencia en principios orientadores de carácter absoluto de aplicación universal, así como la defensa ahistórica de valores tales como el bien común, la dignidad y la armonización de las relaciones sociales como forma de evitar los conflictos. Aunque estos rasgos fueron señalados para una experiencia profesional concreta, presentan una cierta universalidad que también es apreciable en la forma en la profesión es asumida en otras latitudes. De manera específica los mismos rasgos señalados que apelan a una moral universal abstracta se aprecian con total claridad en la definición de la profesión que aparece en un Manual de Derechos Humanos y Trabajo Social elaborado por la ONU (1995) con aportes de la Federación Internacional de Trabajo Social (FITS): "El trabajo social halla sus diversos orígenes en los ideales humanitarios y democráticos. La práctica del trabajo social se ha centrado desde sus comienzos en la

\footnotetext{
${ }^{5}$ El término desarrollo humano está signado por lo demás por un fuerte contenido reformista, en tanto se asume que las consecuencias indeseadas resultantes del modo de producción capitalista, pueden ser mitigadas a partir de acciones políticas redistributivas que tenderán a humanizarlo.
} 


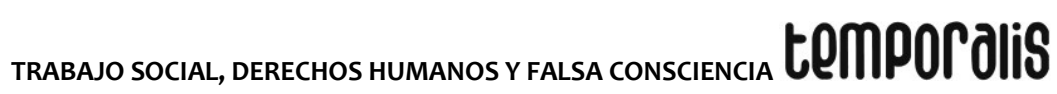

satisfacción de las necesidades humanas y en el desarrollo del potencial y los recursos humanos (ORGANIZAÇÕES DAS NAÇÕES UNIDAS, 1995, p. 13).

Más adelante, cita textualmente una cita del Código Internacional de Ética de la Federación Internacional de Trabajadores Sociales que indica lo siguiente:

Los trabajadores sociales profesionales se consagran a fomentar el bienestar del ser humano y a potenciar su realización, además de desarrollar y aplicar con disciplina tanto los conocimientos científicos relativos a las actividades humanosociales (sic) como los recursos destinados a satisfacer las necesidades y las aspiraciones de individuos y grupos nacionales e internacionales y al logro de la justicia social (FITS citada en: ORGANIZAÇÕES DAS NAÇÕES UNIDAS, 1995, p. 13).

Como puede apreciarse la propia profesión de Trabajo Social es definida en términos axiológicos, apelando para ello a una esencia humanista abstracta. Con ello se la presenta como una práxis profesional esencialmente bondadosa y comprometida con una noción de bienestar también abstracta. Esta autoconcepción ideológica es la que permite la convergencia e integración de las concepciones despolitizadas de los Derechos Humanos. Ahora bien, cuando estos rasgos ideológicos confluyen con tendencias pragmatistas ${ }^{6}$ que sobrevaloran la intervención como espacio exclusivo de materialización de la teleología profesional, se explica cómo opera la confluencia del iusnaturalismo con el positivismo. Herrera (2014) critica esta absorción pragmática del discurso oficial señalando que:

[...] [el Trabajo Social se caracteriza] por una especie de naturaleza o esencialidad que supuestamente posee, se auto-identifica y auto-retrata como defensor de ciertos valores, permitiéndole apropiarse de Derechos Humanos sin la necesidad de profundizar en sus fundamentos, abordándolos predominantemente desde una postura axiológica, previa constitución de un ethos imaginario, único y armonioso de profesión (HERRERA, 2014, p.87)

Como puede apreciarse, los derechos humanos son refuncionalizados para que ocupen el papel que antaño ocuparon los siete principios del Trabajo Social7, siendo que este categórico universal viene a ser ocupado ahora por el discurso del enfoque de derechos. Esta absolutización es posible solo desde una fundamentación iusnaturalista de dichos derechos, sin embargo, otro giro discursivo hace posible la presencia simultánea del iuspositivismo, lo cual se aprecia con claridad en la siguiente cita extensa.

\footnotetext{
${ }^{6}$ Por tendencia pragmatista en Trabajo Social, se entiende aquellas concepciones que rompen la unidad teoría-práctica, de manera que la primera se somete a la segunda. Esta subordinación puede asumir varias manifestaciones, por ejemplo, el saber se subordina al hacer y la investigación a la intervención, con lo cual la efectividad más inmediatista se viene a convertir en criterio de verdad y validación. Por otra parte, los márgenes abordaje de la producción de conocimiento especializado estarían limitados en relación a las necesidades interventivas, o lo que es igual, se debe investigar lo estrictamente necesario y con finalidades de aplicación a la realidad. Para profundizar al respecto ver Villegas-Herrera (2012)

7 Estos fueron propuestos por el sacerdote católico y trabajador social estadounidense Felix Biestek (1973), y constituían una serie de pautas orientadoras para la interacción entre el agente profesional y la población atendida. Esta propuesta se particulariza por reducir la reflexión ética a una dimensión estrictamente operativa limitada a la intervención inmediata. Para observar una actualización de esta propuesta ver el trabajo de Banks (1997), para una crítica de la misma ver Villegas-Herrera (2016).
} 
La forma en que la profesión se centra en las necesidades humanas determina su convicción de que la índole fundamental de esas necesidades exige que se satisfagan, y no por decisión personal, sino como un imperativo de justicia básica. Por ello, el trabajo social avanza hacia la consideración de los derechos humanos como el otro principio de organización de su práctica profesional. La transición de la orientación hacia las necesidades a la afirmación de los derechos se ha hecho imprescindible porque es preciso satisfacer las necesidades sustantivas tangibles. Una necesidad sustantiva puede traducirse en un derecho positivo equivalente y el goce de ese derecho es algo que se espera faciliten el Estado y entidades más allá del Estado (HERRERA, 2014, p. 14).

La persistencia de nociones absolutas tales como imperativo de justicia básica y de manera central el de necesidades humanas, permite mantener el núcleo iusnaturalista inalterado en el plano de la idea, siendo que para que la operación se vea completa es necesario crear su equivalente jurídico. Es aquí donde el discurso ideológico de la cita realiza un viraje, donde se plantea que una propiedad humana esencial contenida en las necesidades, puede ser traducida al derecho positivo, para lo cual es necesario contar con la voluntad y la acción del Estado.

Con este recurso se crean las condiciones para la convergencia que se viene señalando desde páginas atrás, y sobre la cual Herrera (2014) indica que:

El fundamento aquí es estrictamente iuspositivista, en tanto enmarca la comprensión de Derechos Humanos reducida a su existencia en la norma-positiva (constituciones, reglamentos, decretos, actos, convenios). El proceso generacional, que se incluye aquí, se encuentra igualmente incorporado a esta noción armoniosa-evolutiva de la legalidad; esto implica la reproducción del imaginario liberal del progreso infinito teniendo ahora por causación la creación de mecanismos jurídico-normativos cada vez más completos (HERRERA, 2014, p. 77).

Como se observa, la profesión plantea esta confluencia de ambas concepciones a partir de la separación abstracta que se realiza entre idea y acto. En ella los Derechos Humanos representan un ideal de bien común y por lo tanto deben ser incorporados como principio constitutivo profesional, sin embargo, si se ha de actuar con ellos necesariamente se debe recurrir a la normativa existente. Dicho en otras palabras, los Derechos Humanos son esencialmente buenos, y la forma en que estos se manifiestan es a través de las normativas jurídicas.

Con ello se crea una suerte de tautología, en la que el bienestar no se logra por el irrespeto a la normativa internacional, y por lo tanto la práctica profesional debe desplegar sus acciones para evitar que esto sea de esta manera o bien para normalizar la situación. La tautología consiste en que la propia normativa es asumida como bienestar en sí misma, con lo cual pasa de ser un medio que posibilita y fundamenta la intervención, a convertirse en el fin de la misma.

Como esto último, se aprecia que la falsa consciencia se completa a partir de una triple axiologización que comprende a la profesión, a los sujetos que atiende y a los Derechos Humanos. Con respecto a la primera, las citas analizadas no dejan lugar a duda respecto a la autorepresentación benefactora del Trabajo Social. Los sujetos por su parte reciben un 


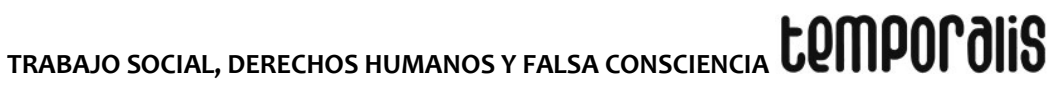

tratamiento similar, en tanto se les asume como personas abstraídas de la realidad que presentan necesidades homologables y generalizables más allá de cualquier mediación que les particularice en estructuras de clase, género o raza. En otras palabras, el sujeto de derechos del discurso oficial, no constituye un sujeto histórico; debido a que sin distingo de sus condiciones particulares, todos se verán necesariamente representados y reconocidos en la normativa. Finalmente, esta concepción es completada con el tratamiento axiológico que se da a los Derechos Humanos, tanto de la norma en sí misma (por cuanto materializa esencialidades humanas inalienables) y del ordenamiento jurídico (en cuanto posibilita acciones de garantía).

El resultado de ello es una falsa consciencia de la realidad en la que la triada Derechos Humanos-Sujetos de derecho-Trabajo Social (DH-SD-TS) constituye una totalidad armónica, en tanto ninguno de sus elementos es objeto de crítica o cuestionamiento, y particularmente, ninguno de ellos se reconoce como portador de contradicciones capaces de negar el goce de los derechos.

Sin embargo, esta armonía construida a partir de la abstracción del conflicto, tiene un límite objetivo, ya que puede ser rota cuando la falta de voluntad política se materializa en lo que organismos como la ONU denominan con el término de regímenes autoritarios, que lejos de garantizar los derechos se convierten en su principal violador, llegando inclusive a adaptar su propio ordenamiento jurídico para ello ${ }^{8}$.

Cuando el Estado decide no entrar en la ecuación, puede evadirse la necesidad de historizar el por qué, recurriendo nuevamente al iusnaturalismo para mantener así la falsa consciencia.

\begin{abstract}
Los derechos humanos son inseparables de la teoría, los valores, la ética y la práctica del trabajo social. Hay que defender y fomentar los derechos que responden a las necesidades humanas; y esos derechos encarnan la justificación y la motivación de la práctica del trabajo social. Por consiguiente, la defensa de esos derechos debe formar parte integrante del trabajo social, aunque en los países que viven bajo regímenes autoritarios esa defensa puede tener graves consecuencias para los trabajadores sociales profesionales (ORGANIZAÇÕES DAS NAÇÕES UNIDAS, 1995, p.15).
\end{abstract}

La cita refuerza la idea de que la triada DH-SD-TS tiende intrínsecamente a la armonía. Este recurso discursivo es indispensable para pensar la inherencia de los derechos y la universalidad de los mismos. Para que esta pretensión sea sostenible en contextos donde la conflictividad es objetivamente insoslayable, estos serán concebidos como ejemplos de

situaciones de irregularidad política, y que necesariamente constituyen exterioridades a la triada. Dicho de manera sintética, la existencia de condiciones de inseguridad que impidan el goce y la defensa de derechos, no altera en sí mismo el núcleo armónico de la triada, dado que la meta de esta es volver a una situación de estabilidad.

\footnotetext{
${ }^{8}$ Piénsese, por ejemplo, la forma en que la promulgación de leyes antiterroristas crean las condiciones para regímenes autoritarios puedan ejercer legalmente terrorismo de Estado, aún más allá de sus propias fronteras.
} 


\section{temporalis}

Por otra parte, la cita es paradigmática respecto al carácter abstracto del término régimen autoritario. En una forma de razonamiento circular, estos son comprendidos como aquellos Estados-Nación que no respetan la normativa internacional, y que por lo tanto se han desviado de la misma, sin embargo, lo que resulta significativo es que ninguna parte de este manual problematiza las razones por las cuales grupos particulares materializan proyectos políticos en los cuales las garantías individuales y colectivas (aún las liberales) son negadas a partir del uso de la violencia política?.

Esta forma particular en que los derechos humanos han sido incorporados como falsa consciencia a la profesión es susceptible a varias críticas radicales, entre las que se pueden señalar cuatro esenciales. La primera de ellas tiene que ver con la alienación que se realiza de los derechos humanos en el plano de la consciencia, en la cual estos a partir de su carácter de bondad absoluta, pasan a convertirse de medios, a fines en sí mismos. Dicho en otras palabras, el goce de los derechos humanos se convierte en el estadio máximo de realización humana, y consecuentemente en su aspiración última.

En segundo lugar, tenemos que el sesgo liberal manifiesto en la fundamentación iuspositivista, abre las posibilidades para convertir el ejercicio de los derechos humanos en una praxis reiterativa que bloquea la transformación social mediante la fetichización de las leyes; esto es que la limitación de los derechos humanos a la normativa jurídica existente tiende darle vida propia a dichas leyes, con las consecuencias de que: se generan prácticas mecanicistas en torno a sus enunciados formales, se niega el carácter histórico de las mismas, y se termina finalmente en una reificación del orden hegemónico existente. Con ello el problema del goce de derechos no sería de naturaleza política, sino técnicoinstrumental.

En un caso extremo, la recurrencia compulsiva al orden jurídico puede llevar incluso a la utilización de las normas para violentar las propias normas. Por ejemplo, la promulgación de una ley que busque otorgar derechos a la figura de familia puede derivar en la objetivación de una subjetividad conservadora, mediante la promulgación de leyes que determinen que bajo esta figura solo tiene cabida la familia tradicional, conformada por padre, madre e hijos. Con ello, un legislador procedente de grupos conservadores religiosos puede llegar a darle rango de ley a una concepción excluyente de la realidad, revistiendo con ello de legalidad a prácticas discriminatorias.

Sin embargo, las críticas más profundas surgen como una consecuencia de las anteriores. La tercera es que este posicionamiento tiende a invisibilizar las estructuras de dominación existentes en la sociedad global, entre las cuales la propia ONU destaca como una de ellas ${ }^{10}$.

\footnotetext{
9 De hecho, la única observación al respecto se caracteriza por la vaguedad, la simplificación y una comprensión lineal de la historia: "Innumerables personas han sido asesinadas o torturadas, o han desaparecido, en un mundo sometido a la dominación y la opresión. Los sistemas y estructuras explotadores y opresivos dan lugar a dictaduras y regímenes autoritarios, bajo los cuales millones de personas son víctimas de violaciones de sus derechos humanos como precio de su lucha por la libertad y la supervivencia" (ORGANIZAÇÕES DAS NAÇÕES UNIDAS, 1995, p. 15).

${ }^{10} \mathrm{El}$ prontuario de las misiones de pacificación llevadas a cabo por la ONU, muestra que, en múltiples ocasiones, los propios cuerpos militares de este organismo terminan convirtiéndose en violadores de los derechos humanos en los territorios que llegan a pacificar.
} 


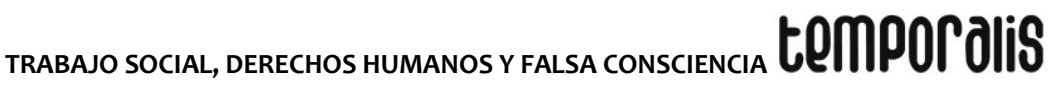

Existe en esta posición una clara ausencia de la geopolítica y ordenamiento mundiales como referente histórico, a la vez que el carácter absoluto que se le atribuye a los derechos humanos muestra la tendencia a disolver la diversidad de la experiencia humana en nociones abstractas de universalidad.

Finalmente, se presenta la mayor limitación que se encuentra en el propio núcleo ideológico del posicionamiento, y es la negación de la conflictividad social, la cual no vendría a formar parte del propio entramado de los derechos humanos. De hecho, esta constituiría un efecto externo y no deseado que resulta de la violación de los derechos humanos, con lo cual se soslaya de paso la trascendencia de los movimientos sociales y las prácticas de resistencia que luchan por el goce de los derechos y por la ampliación de las normativas existentes.

\section{EL ULTRAIZQUIERDISMO IDEOLÓGICO Y LA CRÍTICA A LOS DERECHOS HUMANOS}

Hasta el momento la reflexión ha girado en torno a la incorporación de los Derechos Humanos en el acervo ético-político del Trabajo Social desde una perspectiva ideológico conservadora. Si bien esta corresponde a una posición que podría denominarse como hegemónica, lo cierto es que no es la única.

Dado que lo que movilizó este trabajo fue analizar la forma en que se produce una forma particular de falsa consciencia, es necesario reflexionar sobre otra forma en que esta se genera en el extremo opuesto del espectro político, en lo que podría denominarse con el término de crítica ultraizquierdista de los Derechos Humanos ${ }^{11}$.

Una diferencia sustancial con la posición previamente analizada es que su producción discurre más por el campo de la subjetividad que por el de la producción bibliográfica propiamente dicha, o lo que es lo mismo, existe de manera tácita más como una suerte de sentido común sociológico, que como una postura formalmente trabajada y explícitamente materializada.

De manera sintética la crítica ultraizquierdista propone un rechazo abierto de los Derechos Humanos, utilizando para ello la categoría de clase social de manera unilateral. En ella, se lleva hasta sus últimas consecuencias la crítica del binomio concesión-conquista ${ }^{12}$, en donde los derechos son concebidos como una concesión estrictamente funcional a los intereses de la burguesía, de manera tal que la pretensión de incorporarlos en el horizonte ético-político derivará necesariamente en la reproducción de la sociedad capitalista. Ante esta situación, si lo que se pretende es la emancipación de la humanidad a partir de la abolición de las clases sociales, lo que cabe es su rechazo.

\footnotetext{
11 Sobre este aspecto es importante realizar una aclaración. La compresión del vínculo entre Derechos Humanos e Ideología en el marco de la profesión de Trabajo Social, está lejos de agotarse en la dicotomía Conservadurismo-Ultraizquierdismo. El presente trabajo se centró exclusivamente en las formas de falsa consciencia, siendo que es de esta manera que se presentan estos dos polos opuestos que están lejos de contener toda la producción de visiones de mundo vinculadas a la discusión de los Derechos Humanos.

${ }^{12}$ Para un análisis de este par categorial ver: Pastorini (2000).
} 


\section{tomporalis}

Muy a pesar del lenguaje crítico con el que esta forma de sentido común suele plantearse, lo cierto es que constituye el error simétrico de la ideología conservadora de los Derechos Humanos previamente analizada. La razón de ello radica en que al igual que la tendencia anterior, también asume una perspectiva axiológica y esencialista de los mismos, con la diferencia de que en este caso se les asigna una valoración negativa. Dicho de manera sintética, mientras en la falsa consciencia conservadurista los Derechos Humanos son planteados como la materialización de una esencialidad irreductiblemente benefactora, en la falsa consciencia ultraizquierdista se plantean como portadores de una esencialidad irreductiblemente burguesa, y por lo tanto deben combatirse.

Esta postura necesariamente deriva en una deshistorización que es posible debido a tres factores. En primer lugar, extrapola las posibilidades históricas de la profesión, asignándole un papel histórico al agente profesional que no le corresponde, este es el de asumirse como como intelectual orgánico del proletariado, así como asignarle una misión emancipatoria y revolucionaria que no le corresponde a la profesión de Trabajo Social, ni a ninguna otra.

En segundo lugar, parte una comprensión mecanicista y lineal de la historia en la que los Derechos Humanos quedan reducidos a la manifestación de una estrategia de la burguesía esencialmente reaccionaria. En este caso surge una diferencia con la tendencia conservadurista, ya que la falsa consciencia no radica tanto en la invisibilización del conflicto de clase (piedra angular de la postura anterior), como sí en una sobredimensión del mismo que lo vuelve incomprensible. Con ello la crítica ultraizquierdista termina por imponerle a la realidad la comprensión teórica que busca explicarla, o lo que es lo mismo, opera una escisión de la unidad teoría-práctica donde la primera anula y subordina a la segunda.

Finalmente, la negación a priori el carácter contradictorio de los Derechos Humanos, termina invisibilizando cualquier posibilidad emancipatoria en estos. Dicho en otros términos, la falsa consciencia ultraizquierdista asume los Derechos Humanos de manera exclusiva como realidad, sin llegar a dimensionarlos como parte del devenir histórico, como posibilidad.

La superación de esta forma particular de falsa consciencia parte de reconocer el carácter histórico de los Derechos Humanos, que aún en el caso constituir una concesión reaccionaria, no están exentos de contradicciones que abren posibilidades de emancipación. Al respecto, Santos Neto (2011) nos recuerda lo siguiente:

Os direitos humanos são tão-somente necessários devido à condição de miséria em que vive a humanidade, em que o trabalho é submetido à regência do capital. Os direitos humanos são fundamentais apenas porque a humanidade ainda não alcançou o reino da liberdade e permanece num nível de sociabilidade em que a maioria de seus partícipes não tem acesso às riquezas produzidas para atender suas necessidades fundamentais (SANTOS NETO, 2011, p.179).

Como se aprecia, los Derechos Humanos abre posibilidades para la restauración de condiciones básicas en la materialidad de la existencia humana. Sin esta última, y en un 


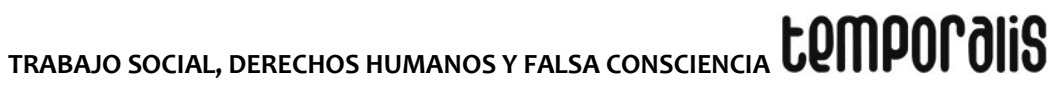

momento histórico en el que aún no se ha dado la emancipación, estos no sólo serían útiles sino además necesarios para abrir posibilidades a dicha emancipación.

Contrario a la comprensión deshistorizante de la crítica ultraizquierdista, la realidad objetiva ha mostrado que los derechos humanos distan mucho de ser una concesión unilateral de las clases dominantes, sino que por el contrario son el resultado de luchas concretas que han propiciado su génesis y exigibilidad. Así mismo, esta forma de falsa consciencia pasa por alto el hecho de que las clases dominadas han generado procesos de apropiación subjetiva de dichos derechos, lo cual ha favorecido la resistencia, la movilización y la lucha para su mantenimiento y ampliación.

\section{ELEMENTOS PARA UNA SUPERACIÓN DE LA FALSA CONSCIENCIA DE LOS DERECHOS HUMANOS}

A manera de conclusiones, el aporte final de este artículo es presentar algunos elementos para una recuperación crítica de los derechos humanos, que en el entender de Gallardo (2004) implica por lo menos el reconocimiento de dos condiciones. La primera de ellas es la necesidad de que la fundamentación de los derechos humanos parta de que estos sean testimoniados, esto es que conformen parte de la experiencia humana en el espacio de la vida cotidiana. La segunda condición, tiene que ver con la afirmación del autor de que los derechos humanos no existen a no ser como manifestación de lucha para su defensa y goce, lo cual implica reconocerlos como materialización de la lucha y el conflicto social en contextos de hegemonía particulares.

Para ello es indispensable tener en cuenta cuatro consideraciones fundamentales.

a) Crítica a la inversión de los derechos humanos. Es necesario para una recuperación crítica de los derechos humanos, el reconocer el desarrollo de toda una tradición ideológicocultural en las sociedades capitalistas occidentales que ha permitido y legitimado la violación de los derechos humanos en nombre de los propios derechos humanos. Hinkelammert (1999) señala que este proceso de inversión inicia en las sociedades modernas con los planteamientos de John Locke, que buscaba legitimar la esclavitud en nombre de la libertad. Al respecto nos dice:

[... ] el culpable [de violar derechos] debe ser destruido toda vez que es 'un peligro para el género humano', es un 'degenerado', un 'ser dañino' que ha atropellado 'la especie toda' y debe ser tratado como una fiera salvaje. Él se ha levantado en contra del género humano, puesto que ha manifestado que 'con él no rige la ley de la razón'. Al cometer el crimen, ha renunciado hasta a sus derechos humanos. Es, en fin, un ser por aniquilar. (comillas en el original) (HINKELAMMERT, 1999, p. 23).

Es claro que esta estratagema permitió a un autor como Locke justificar los procesos de colonización y el comercio esclavo sin entrar en contradicción con los ideales de la llustración. Ahora bien, en condiciones contemporáneas, esta forma de invertir los derechos ha permitido legitimar otras prácticas de agresión imperialista bajo la consigna de ningún derecho humano para los enemigos de los derechos humanos, lo cual faculta inclusive el desarrollo de prácticas de represión con carácter preventivo contra aquellas personas que sean juzgadas como una amenaza por parte de quienes detentan el poder. 


\section{temporalis}

El grado superlativo de esta tendencia puede observarse cuando sobre esta base se llega a negar la humanidad de quienes "amenazan el orden" y con ello cancelar de manera absoluta los derechos humanos. El reconocimiento de este tipo de praxis en nombre de los derechos humanos nos muestra que estos no encierran de ninguna manera un carácter de bondad absoluta.

b) Reconocimiento de las limitaciones del Estado de Derecho. Como una consecuencia de lo anterior, Hinkelammert (2005) señala que la confianza a ultranza en el ordenamiento jurídico puede llevarse a cabo sólo a partir de una mistificación de la legalidad. Si a este elemento se le suma el hecho de que en un contexto de globalización neoliberal los estados nacionales particulares pierden importantes cuotas de autonomía, tenemos como consecuencia que es esperable que se genere una praxis política hegemónica en la cual se da una integración de la dictadura de seguridad nacional con en el estado de derecho y el vaciamiento de la democracia a su mera formalidad.

Gallardo (2004) es tajante al afirmar que: "El Estado moderno no es un aparato de comprensión universal y por tanto no puede ser fundamento de caracteres universales ni reconocerlos. Se lo impiden sus funciones de dominación y la impronta geopolítica de las relaciones internacionales (GALLARDO, 2004, p.12).

Como resultado de esta reflexión tenemos que no puede afirmarse la universalidad de los derechos humanos, y menos presentar al Estado de Derecho como garante de esta, dado que este no sólo sigue las tendencias globalizadoras antes mencionadas, sino que también es susceptible a verse afectado por fenómenos como la corrupción y el crimen organizado. c) Comprensión del orden geopolítico capitalista como contexto histórico determinante. La necesidad de historizar los derechos humanas implica el reconocimiento de las condiciones mundiales en los que se configuran las relaciones entre Estados. Específicamente, debe observarse que el signo económico capitalista de este proceso constituye el obstáculo central para su realización universal. Gallardo (2004) plantea que:

[...] la acumulación de capital no puede ser matriz de derechos humanos por diversos motivos de los que indicaremos tres: contiene una lógica de discriminación que produce ganadores y perdedores; reifica mercantilmente la experiencia humana reduciendo la plenitud posible de esta experiencia a consumo u opulencia; propone un orden absoluto desde el que se puede agredir la diversidad humana o sus experiencias individuales diversas (GALLARDO, 2004, p. 19).

Este argumento, muestra en todos sus alcances los límites formalistas de las propuestas liberales, al punto de que el reconocimiento de ciertos derechos (por ejemplo, el de la propiedad privada) solo puede darse a partir de la violación de otros. Esto es así debido a que la lógica de acumulación de ganancias en el capital se establece como criterio jerarquizador de derechos, más allá de que formalmente el discurso oficial niegue la existencia de dicha jerarquización.

d) Crítica de la ética e ideología neoliberales como incompatibles con los derechos humanos. Una última crítica pasa por reconocer los límites de un ethos profesional ante la existencia y consolidación de un ethos cultural hegemónico configurado por el neoliberalismo. Esto 


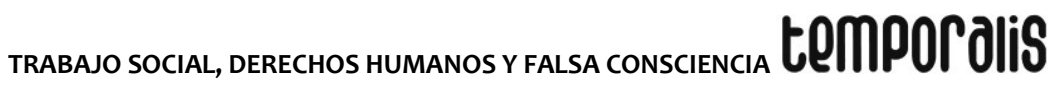

implica que no basta declarar discursivamente la existencia de un proyecto profesional centrado en el enfoque de derechos, sino que además necesariamente obliga a reconocer los obstáculos que este ha de enfrentar.

La ética neoliberal ha sido caracterizada por Gómez (1998) a partir de rasgos como: el sostenimiento de valores como el egoísmo, la ambición, el éxito, el individualismo y la competitividad; lo cual trae como consecuencia la naturalización de una sociedad con ganadores y perdedores, donde los primeros son titulares a la hora de exigir derechos.

Dussel (1997) por su parte, señala otros rasgos del discurso neoliberal, tales como la irreversibilidad histórica del capitalismo, el darwinismo social como mecanismo de mejoramiento de la sociedad, así como el carácter absoluto de la racionalidad del proyecto hegemónico, que lo define consecuentemente como incuestionable.

Toda esta argumentación hace parte de la racionalidad instrumental del proyecto neoliberal, que reviste de una gran trascendencia, debido a que es a partir de esta que se justifican los ataques a los Estados de Bienestar, que contradictoriamente aparecen en el discurso oficial de Naciones Unidas como los garantes del enfoque de derechos humanos. Esta contradicción es posible gracias al principio de progresividad del enfoque de derechos de la ONU, esto es que los Estados están obligados a garantizar los derechos humanos (particularmente los económicos y sociales) en el marco de sus posibilidades. Si estas posibilidades no existen, por ejemplo, a causa de las políticas neoliberales impuestas por otras instituciones de la globalización como el FMI o el BM, no existiría desde el punto de vista estrictamente formal un conflicto de incumplimiento.

Como corolario a esta reflexión cabe reforzar una reflexión adicional, y es que la recuperación crítica de los Derechos Humanos necesariamente debe partir del reconocimiento de un escenario de conflicto, así como del posicionamiento dentro de él. En este sentido Gutiérrez (2000) señala que:

[... ] derechos humanos es lucha por reconstruir el tejido social roto por el orden mundial neoliberal, por reconstruir las comunidades locales, regionales y nacionales fragmentadas por el capital contra los derechos de las personas, comunidades, naciones y pueblos de todo el mundo. Es construir, a pesar de las estructuras de opresión y exclusión, espacios de relaciones sociales nuevas, de resistencia y un modo nuevo de vivir la cotidianidad, las instituciones alternativas y los modos de enfrentar mancomunadamente el orden de muerte (GUTIÉRREZ, 2000, p. 27).

En síntesis, y partiendo de Gutiérrez (1998) para sintetizar la propuesta de este artículo, es indispensable entender que los derechos humanos solo tendrán un potencial emancipador en tanto sean liberados de todo formalismo jurídico, se muestre su incompatibilidad con un sistema económico jerarquizado en torno a la propiedad privada, que se parta del reconocimiento de la humanidad como una experiencia diversa y sobre todo que se piensen en función de la movilización y la resistencia.

\section{REFERENCIAS}

BIESTEK, Felix. Las relaciones de Casework. Madrid, España: Editorial Aguilar, 1973. 
BANKS, Sarah. Ética y valores en el Trabajo Social. Barcelona: Editorial Paidós, 1997. BOBBIO, Norberto. El tiempo de los derechos. Madrid: Editorial Sistema, 1991.

DUSSEL, Enrique. El discurso teórico del pensamiento neoliberal: evolución cultural, libertad individual y mercado. Revista Pasos, San José: Departamento Ecuménico de Investigaciones, n. 71, p. 11-15, mayo/jun.1997.

FERNÁNDEZ, Alejandro. Pobres con defensa pública en desventaja ante la justicia. Semanario Universidad [online], Universidad de Costa Rica. 19 abr. 2017. Disponível em: <https://semanariouniversidad.com/pais/pobres-defensa-publica-desventaja-ante-lajusticia/>.

GALLARDO, Helio. Fundamento y efectividad de los Derechos Humanos. Revista de Filosofía de la Universidad de Costa Rica, San José: Universidad de Costa Rica, n. 105, v. 42, p. 11-36, 2004.

GÓMEZ, Ricardo. Neoliberalismo y ética humanista; una incompatibilidad radical. Revista Pasos, San José: Departamento Ecuménico de Investigaciones, n. 75, p. 24-29, ene./feb. 1998.

GUTIÉRREZ, Germán. Globalización y Liberación de los Derechos Humanos. Una reflexión desde América Latina. Revista Pasos, San José: Universidad de Costa Rica, n. 89, p. 17-27, mayo/jun. 2000.

HERRERA, Omar. Trabajo Social: Formación académica y Derechos Humanos. 2014. Tese (Licenciatura em Trabalho Social)- Escuela de Trabajo Social, Universidad de Costa Rica, San José, Costa Rica, 2014.

HINKELAMMERT, Franz. La Transformación del Estado de Derecho bajo el impacto de la estrategia de globalización. Revista Pasos, San José: Departamento Ecuménico de Investigaciones, n. 117, p. 12-17, ene./feb.2005.

HINKELAMMERT, Franz. La inversión de los Derechos Humanos: el caso de John Locke. Revista Pasos, San José: Departamento Ecuménico de Investigaciones, n. 85, p. 20-35, set./oct.1999.

LÖWY, Michael. Ideologías e Ciência Social: elementos para uma análises marxista. São Paulo: Cortez, 2010.

MONTAÑO, Carlos. La naturaleza del Servicio Social: un ensayo sobre su génesis y reproducción. Sao Paulo: Cortez, 1998.

OFICINA DEL ALTO COMISIONADO DE LAS NACIONES UNIDAS PARA LOS DERECHOS HUMANOS. Preguntas frecuentes sobre el enfoque de Derechos Humanos en la 


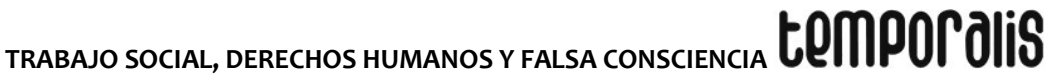

cooperación para el desarrollo. Ginebra, Suiza, 2006. Disponível em:

<http://www.ohchr.org/Documents/Publications/FAQsp.pdf>.

ORGANIZAÇÃO DAS NAÇÕES UNIDAS. Derechos Humanos y Trabajo Social: manual para escuelas de servicio social y trabajadores sociales profesionales. Ginebra. Suiza: Centro de Derechos Humanos, 1995. (Série Capacitación Profesional, n.1.)

PASTORINI, Alejandra. ¿Quién mueve los hilos de las políticas sociales? Avances y límites en la categoría “concesión- conquista”. Serviço Social \& Sociedade, Sao Paulo: Cortez, n. 53, 2000.

SANTOS NETO, A. A constituição histórico-ontológica da ética e dos direitos humanos. Katálisys, Florianópolis: Universidade Federal de Santa Catarina, v. 14, n. 2, p. 172-181, jul./dez. 2011.

VILLEGAS-HERRERA, César. Trabajo Social y producción de conocimiento teórico: Un análisis del vínculo existente entre la investigación y la construcción de legitimidad profesional en la Escuela de Trabajo Social de la Universidad de Costa Rica. 2012. Tese (Mestrado em Serviço Social)- Universidad de Costa Rica, 2012.

VILLEGAS-HERRERA, César. Trabajo Social y conservadurismo ético-político. Un análisis del discurso ético profesional en Costa Rica. Conceptos, Ciudad Autónoma de Buenos Aires: Universidad del Museo Social Argentino, año 91, n. 498, dez. 2016. ISSN Nº 03277860. 